\title{
Four new dinoflagellates
}

\author{
Enrique Balech \\ Estación Hidrobiológica de Puerto Quequén; Casilla de Correo 64, 7630 Necochea, \\ Argentina
}

\begin{abstract}
Fragilidium fissile is a new species of this rare genus. It somewhat resembles $F$. subglobosum. It differs from the latter in having a slot and a pore in the first apical plate 1' (the nomenclature of dinoflagellate plate designation follows the Kofoid system). Both species are also distinguishable by noticeable differences in $\mathrm{Po}_{1} 1^{\prime \prime \prime}$ and $1^{\prime \prime \prime}$. Peridinium tyrrhenicum is a small species differing from all the other known species of Peridinium in its shape, apical channel and several plates, especially some of the sulcal components. Alexandrium foedum somewhat resembles A. balechii, but it differs from the latter in that its width is greater than its length, and in the characters of all the main sulcal plates. The above listed species were found in a sample from the Tyrrhenian Sea. The fourth species, Alexandrium andersoni, is a small dinoflagellate obtained in coastal waters off Cape Cod. It differs from all the other species of the minutum group in the very typical shapes of both the 6" and the S. s. Pentapharsodinium daleii Indelicato and Loeblich is transferred to Peridinium.
\end{abstract}

\section{INTRODUCTION}

During the revision of material received from different countries in my search for dinoflagellates of the genus Alexandrium, some new or very rare species were found, some belonging to the genus just mentioned, some to other genera. Most of the species not belonging to Alexandrium were left aside for a future, detailed study. However, two new species found in the Gulf of Salerno were considered of special interest and they are therefore presented here, together with two new Alexandrium.

One of the species is a Fragilidium, quite a rare genus which presents, in addition to its rarity, the interesting aspect of its usual association with dense populations of some "Gonyaulax s. 1.", upon which it often feeds. The other species belongs to Peridinium s. str., a genus almost unknown in sea waters.

Two new Alexandrium were also found, one in the same sample from the Gulf of Salerno, and the other near Cape Cod on the Atlantic coast of North America.

\section{MATERIALS AND METHODS}

The material studied was found in a rich plankton sample from the Gulf of Salerno, Italy, that had been kindly sent by Dr. A. Zingone, from the Stazione Zoologica di Napoli, and in a sample of a clonic culture isolated and maintained in the Woods Hole Oceanographic Institution by Dr. D. R. Anderson. The latter clonic culture is based on a cell obtained near the shores of Cape Cod.

Many thecae of every species herein presented were isolated, oriented, drawn and 
measured and thereafter subjected to the usual treatment with sodium hypochlorite for the separation of the plates. The plates were examined under immersion oil and with phase contrast. The thecae of Alexandrium andersoni were also stained with iodine and Cresyl blue.

In the description, the measurements are always expressed in $\mu \mathrm{m}$ and thus the symbol is often omitted. The following abbreviations have been used: L for length, Trd for transverse diameter (transdiameter), and A for maximum width.

\section{DESCRIPTIONS AND DISCUSSIONS}

\section{Fragilidium fissile n.sp.}

Fragilidium fissile n. sp. (Figs 1-11). Medium size, spheroidal. Epitheca somewhat convex-conical with a discernible apical protrusion. Hypotheca regularly rounded (Fig. 1) or, more frequently, with a slight antapical flattening. Cingulum regularly but not deeply excavated, without lists, descending about $0.5-0.75$ width. Thecal walls very thin. Normal plate pattern: Po,4', 8", 9-10 C, $7^{\prime \prime \prime}, 2$ "', 1 P and $7 \mathrm{~S}$.

Po is large, irregularly oval-rhomboidal with two dorsal sides of equal or different lengths, and two longer ventral sides tapering to an acute ventral angle. The right ventral margin is straight to concave, and the left one straight to gently convex. Sometimes the right angle is briefly truncated. Inside this plate, there is a long and narrow slot in the shape of a somewhat irregular walking cane with thickened borders. All around the slot there are many pores.

There are four apical plates: the fourth is six-sided and is the smallest; 1 ', sevensided, is much bigger. The $2^{\prime}$ is larger than in other species and it is almost triangular with a truncated apex. The $3^{\prime}$, six-sided, is also wider than in other species.

The 1" (clearly the homologue of $1^{\prime}$ of Alexandrium) is narrow, rather high, with a short reinforced cingular border, two right borders of about the same length, a longer left margin and a short and steeply slanting anterior one (or left-anterior).

In the hypotheca, the first post-cingular is narrow-trapezoidal in shape, its length more than doubling its width. Its reinforced internal margin is slightly concave anteriorly and slightly convex posteriorly. The $7^{\prime \prime \prime}$ is trapezoidal wider behind. Because of its position, this plate is more a perisulcal ("antapical") plate than a postcingular.

The first antapical is essentially five-sided, transversally and obliquely elongated and narrowing to the left-dorsal end. The second antapical is of almost the same length in the transversally oblique direction but is conspicuously wider.

The plate $P$ is very large and asymmetrically pentagonal.

The sulcal plates are as seen in the Figures 7-11. The most important point to be stressed is that the plates S.s.a. and the S.d.a. are not very long. The S.s.p. is like an axe anteriorly wide. The S.s.a. is four angled, wider than high, and widening a little to the right. The S.d.p. is short. The S.p. is narrow and high (as high as the S.s.p.).

Dimensions: L 44-57. A usually about equal to $L$, sometimes a little shorter: $41-56$; Trd. 3-4 $\mu \mathrm{m}$ less than A.

Discussion: The thecal walls are very thin and most of the specimens are found with the epitheca and hypotheca partially or completely separated; in the first case, both hemithecae join in the ventral part. Not rarely, the three regions (the epitheca, the 

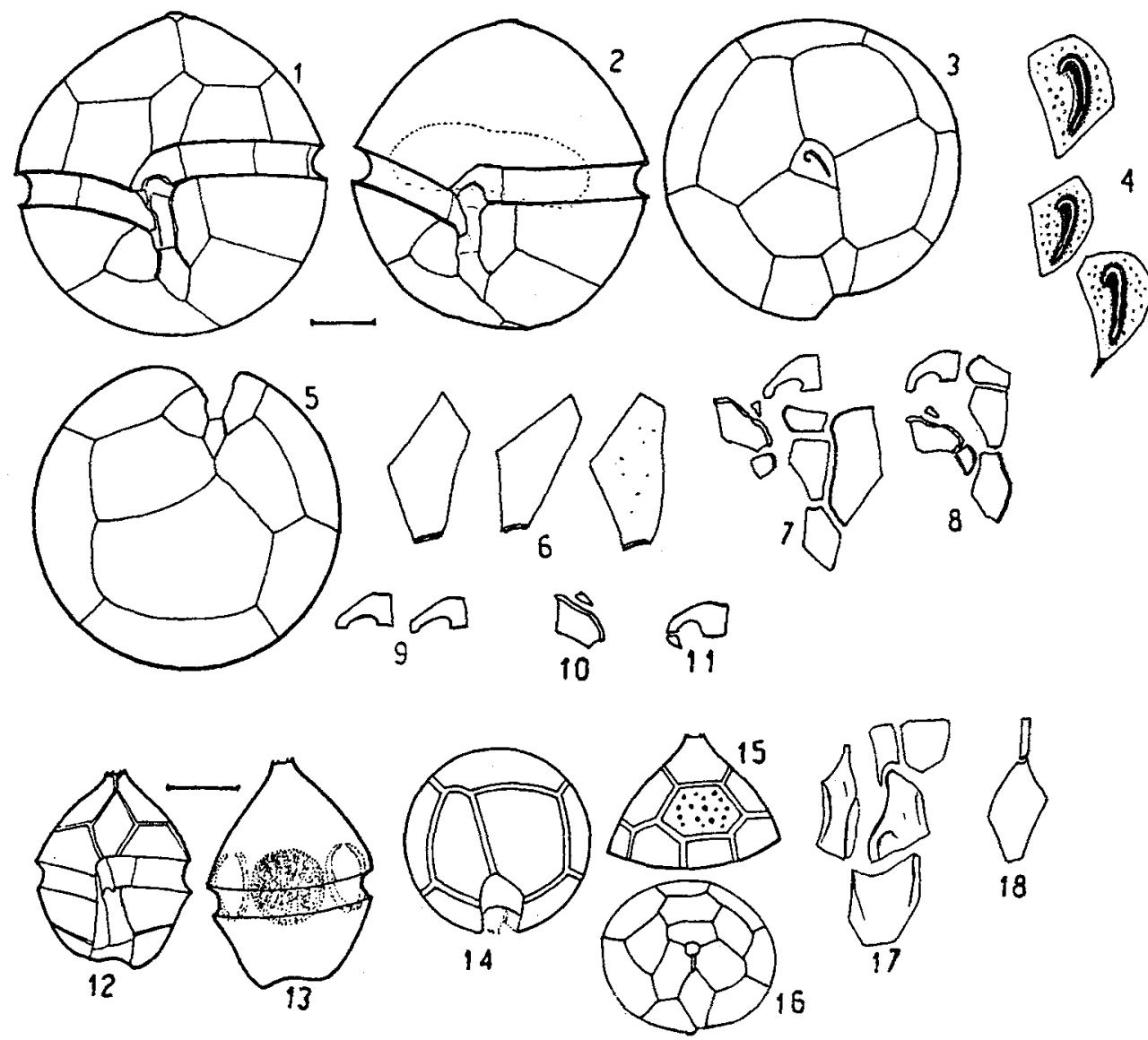

Figs 1-18. Fragilidium fissile and Peridinium tyrrhenicum.

Figs 1-11. Fragilidium fissile; Figs 1-2: ventral view; Fig. 3: Epitheca, apical view; Fig. 4: Apical pore plate (Po) from 3 different specimens; Fig. 5: Hypotheca, antapical view; Fig. 6: Plate 1" from 3 different specimens; Figs 7-11: Sulcal plates

Figs 12-18. Peridinium tyrrhenicum; Fig. 12: Ventral view; Fig. 13: Dorsal view; Fig. 14: Hypotheca, antapical view; Fig. 15: Epitheca, dorsal view with hexagonal plate 2a; Fig. 16: Epitheca, apical view; Fig. 17: Sulcal plates; Fig 18: Plate 1' and very long plate $\mathrm{X}$

cingulum and the hypotheca) join in the ventral region and are completely separated in the rest. This fact introduces some uncertainty concerning the length of the intact cell. Because of the same reason, most of the thecae studies were empty. In the very few specimens with protoplasm, cell contents were rather homogenous and ingested cells were not observed; thus there is no evident phagocytosis as in $F$. heterolobum and in $F$. mexicanum. Nonetheless, it is interesting to note that like other congeneric species F. fissile seems to thrive in waters with abundant, small Gonyaulacidae (Gonyaulax polyedra and Alexandrium spp.)

Most of the thecae have $4^{\prime}$ (only one with $5^{\prime}$ ), $8^{\prime \prime}$ (one with $9^{\prime \prime}$ ), $10 \mathrm{C}$ (two thecae with $9 \mathrm{C}$ ). 
In one epitheca there was a small extra intercalary plate. There were no variations in the hypothecal plate pattern.

Fragilidium is a genus rarely cited and up to now only two species have been recorded: the type species $F$. heterolobum Balech (Balech, 1958), and $F$. subglobosum (v. Stosch) Loeblich which was first described as Helgolandinium subglobosum. In a paper in press I describe another species from the west coast of Mexico, Fragilidium mexicanum and I also transfer Goniodoma lacustre to Fragilidium (Balech, 1988). Thus, the new species has to be compared with those four: only one of them, F. lacustre, is in fresh water. $F$. lacustre is of a quite different shape, with a tall epitheca, much higher than the hypotheca and has 10 precingular and 5 apical plates. The hypothecal plates are also significantly different.

F. heterolobum is of a different shape. Its $1^{\prime \prime}$ is four-sided, $1^{\prime \prime \prime}$ quadrangular, almost square, and all its sulcal plates are different. I would like to stress the very typical S.s.p. of the type species, the short S.p., the small S.s.a. and the very long S.d.a. Besides, it normally has 11 cingular plates.

F. mexicanum has a rather small $1^{\prime}$, smaller than $4^{\prime}$ (the opposite in the new species), its Po is narrower, 1 " is four angled, much shorter and it has, like $F$. subglobosum, a peculiar slot situated near the cingular border ending in a pore; its first antapical is broad and the S.p. is very short.

The closest species is $F$. subglobosum which shares with the new species the globose form, the narrow and high pentagonal 1", the long S.p., the rather short S.d.a., and the shape of both left sulcal plates. However, it has important differences, like the narrow Po, the $1^{\prime \prime}$ with a slot and pore as in $F$. mexicanum, the rather wide $1^{\prime \prime \prime}$ and wide quadrangular $1^{\prime \prime}$.

The epithet "fissile" is a Latin adjective meaning "easily split". Fragilidium fissile has been found in low numbers in the Tyrrhenian Sea, Gulf of Salerno.

\section{Peridinium tyrrhenicum n. sp.}

Peridinium tyrrhenicum n. sp. (Figs 12-18). Small species, pentagonal-pyriform with neither apical nor antapical horns. Epitheca conical, with a slight apical concavity. The apical region shows four very small points, the two internal points corresponding to the optical sections of plate Po, and the two external points corresponding to the raised borders of the apical plates.

The hypotheca has a flattened antapical region with the left angle somewhat protruding. When the theca is seen with the apex a little raised toward the observer, this protrusion becomes more evident. The left side of the hypotheca is somewhat sinuous.

Cingulum excavated, descendent (about 0.5), without lists.

Plate pattern Po, X, 4', 3a, $7^{\prime \prime}, 4 \mathrm{C}$ plus $\mathrm{T}, 5^{\prime \prime}, 2^{\prime \prime \prime}$ and $4 \mathrm{~S}$.

Epitheca of the ortho-hexa type. Plate $\mathrm{X}$ very long, $1^{\prime}$ rhombic of medium width. The fourth precingular is rather low, lower than the hexagonal $2 a$, which is the longest of the intercalary plates.

Regarding the hypotheca, the great dissimilarity of the antapical plates should be stressed, the first one being much smaller than $2^{\prime \prime \prime}$. This fact produces a high asymmetry of $3^{\prime \prime \prime}$, a plate that shows a very short left posterior margin which is about $1 / 3$ the length of the right posterior border. 
The cingulum is formed by 4 plates of almost the same length. At the left end of the cingulum, a transitional or T-plate is added, about as high or a little higher than wide, with a slanting left posterior margin and a short right posterior margin of opposite inclination. This plate is generally somewhat wider anteriorly.

S.a. very narrow, quadrangular, with a posterior margin strongly concave and the right angle projected.

The concavity of the S.a. holds the posterior end of the S.s. which is irregularly triangular with the apex briefly truncated; the posterior margin slants to the right and the posterior part of both lateral sides are strongly curved to the ventral face.

The S.d. has a rather long neck and a body more or less strongly bent holding a slightly differentiated wing, with the free margin convex or bi-convex.

The S.p. is longer than wide, with projected anterior angles, the left one being more protruded. This plate is strongly concave ventrally.

A medium plate was neither isolated nor completely recognized.

The thecal walls are rather thin, hyaline, without sculpture but with rather large pores.

The protoplasm is dark, with chloroplasts, and it always shows two large lateral diplopirenoids at the cingular level. Nucleus spheroidal and central.

Dimensions: L 25.5-33, most of the thecae less than 30; A 21-29; Trd. 20-25.5. The relationship L/A is somewhat variable.

Discussion: On first sight, this dinoflagellate was recorded as a species of Scrippsiella. The plate analysis showed that its sulcal and especially the cingular structures do not fit those found in that genus, but correspond to the genus Peridinium s. str. The finding of a species of Peridinium in marine waters is unusual. Up to now, Peridinium is a genus almost confined to fresh waters, although some thecae belonging to this genus can be found in coastal waters. In this case, it is evidently a species thriving in marine coastal waters since it was well represented in this sample. The species named Ensiculifera loeblichii Cox \& Arnott, 1971, also obtained in marine waters, is not an Ensiculifera but a true Peridinium. Its description is very detailed concerning isolated plates, but lacks details that would help its identification, such as a good figure showing the general shape of the species (see "Discussion" in Dale, 1977). From the plates (l.c., 1971, Figs 1-4) it seems quite oval in shape, differing from the species described here, which has a convexconical epitheca and a regularly rounded hypotheca. Thus, it seems safe to suppose that $P$. loeblichii is different from that described above. Cox \& Arnott (1971) gave no detail of the sulcal plates, which are important taxonomic clues. If Figure 27 represents well the S.d. and the S.p., they both seem different from those in Peridinium tyrrhenicum.

In the same paper in which Dale transfers loeblichii to Peridinium (loc. cit.), he describes another closely related form which he names Peridinium faeroense Paulsen; however, it clearly differs from $P$. faeroense as described by Paulsen (1905) in the epithecal shape and the $1^{\prime}$. Dale's $P$. faeroense was transferred to Scrippsiella by Dodge (1982) as Scrippsiella faeroense, and later on allocated by Indelicato \& Loeblich (1986) to the new genus Pentapharsodinium, as $P$. daleii n.sp.

Dodge's proposal has to be rejected because $P$. faeroense sensu Dale has five cingular plates and thus cannot be accepted in Scrippsiella, a genus with six cingulars. Besides, the combination Scrippsiella faeroense is preoccupied (Balech \& Soares, 1966).

In my opinion, the genus Pentapharsodinium does not have enough substantiation 
and is a synonym of Peridinium. Therefore, accepting the species daleii I propose Peridinium daleii (Indelicato \& Loeblich) as a new combination (= Pentapharsodinium daleii Indelicato \& Loeblich 1986, p. 154). It differs from P. tyrrhenicum in the hypothecal shape, shorter apical channel, tall 4", smaller $2 a$, and in all its sulcal plates, especially its short S.p.

I have not found any freshwater species resembling this new one. This has been kindly confirmed by A. Boltovskoy.

The specific name derives from the Tyrrhenian Sea where the species was found.

\section{Alexandrium foedum n.sp.}

Alexandrium foedum n.sp. (Figs 19-33). Of medium size. In frontal view, its contour is irregularly hexagonal. The sides of the epitheca and hypotheca are somewhat concave at their bases. Both thecal ends are irregularly flattened. The hypotheca is usually slightly slanting to the right and forward. The epitheca is sometimes inclined but in the opposite direction, and, not rarely, depressed slightly in its centre. In lateral view, the theca is

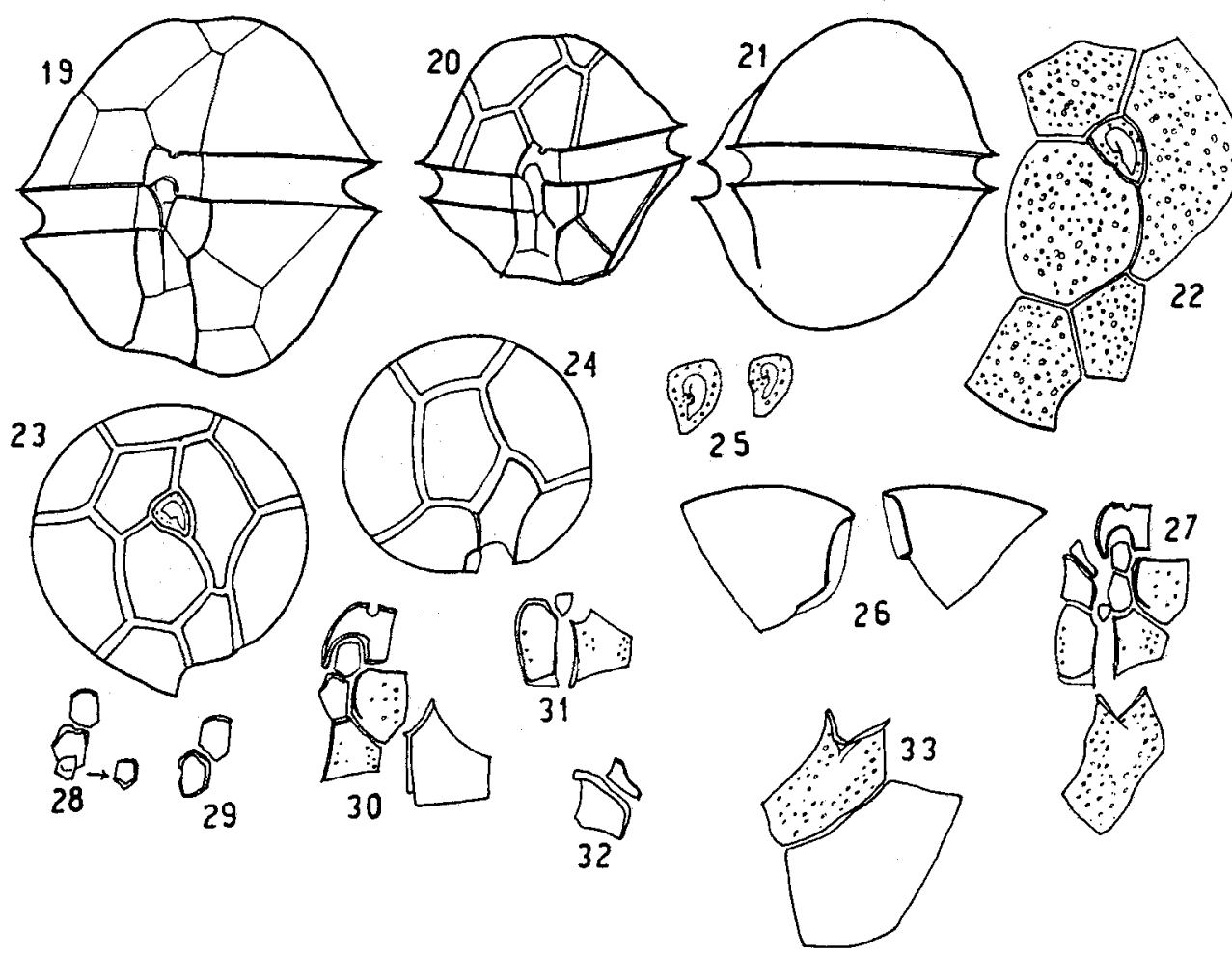

Figs 19-33. Alexandrium foedum. Figs 19-20: Ventral view; Fig. 21: Lateral view; Fig. 22: Apical view of some epithecal plates; Fig. 23: Epitheca, apical view; Fig. 24: Hypotheca, antapical view; Fig. 25: Plate Po of 2 different specimens; Fig. 26: Hypothecal plates $5^{\prime \prime \prime}$ and 1"'; Figs 27-32: Sulcal plates; Fig. 33: Plate S.p. and 2"" 
irregularly elliptical with its longitudinal axis slightly oblique from the anterior-dorsal end to the posterior ventral end.

Cingulum descendent, usually by less than one cingular width (0.5-0.75), strongly excavated, with reinforced margins and narrow but noticeable cingular lists, about $2 \mu \mathrm{m}$ wide.

The Po plate is comparatively small, with comma or central foramen not strongly marked; the callus is poorly developed; irregular marginal pores.

Plate 1' not in contact with Po, far away from it, with two unequal right sides, a rather long posterior or cingular border and a longer left one. There is also an anterior side always very short, sometimes almost pointed and connected to $2^{\prime}$. No ventral pore.

Plate 2 ' ventrally projected in a very narrow section, always much narrower than the dorsal moiety. The $3^{\prime}$ is of the usual asymmetrical six-sided shape.

The last precingular plate is of medium to narrow width; its left posterior side, articulated with S. a., is reinforced and generally concave, sometimes almost straight.

In the hypotheca, 1"' has a short internal border, concave to convex, strongly reinforced, sometimes bearing a very narrow list. The $5^{\prime \prime}$ ' also has a well reinforced internal border, but bears a conspicuous sulcal list as well. 1" $1^{\prime \prime}$ short and wide, with thickened internal margin with no easily detectable sulcal list. 2" about twice as long (dorso-ventral axis) as wide.

The sulcus has several typical features. Because of the curvature of the left end of the cingulum, the S. a. "in situ" seems narrower than it really is, and projects a small point to the right somewhat indenting the epitheca. The indentation of the anterior part of the left sulcal margin is deeper and more obvious than in most of the species because of the thickened margin of $1{ }^{\prime \prime}$, the width of S.s.a. and its superficial location. The posterior end of the sulcus is strongly bent to the right.

The S. p. is long and narrow. Its ventral section is slanting from the ventral end to left and its posterior segment, which is longer, slants to the right. The anterior border, Vshaped, is thickened. This plate has strong irregular pits except in a narrow median zone.

The S. a. is rather narrow, with borders (excepting the left one) thickened. The anterior one is almost straight but interrupted in the middle by a very peculiar round indentation. Deep posterior sinus.

The two lateral-posterior plates are short, expecially the S.s.p. This plate has a long and oblique posterior border, an internal one that is thickened, a very short left posterior border, a left anterior, slanting and about twice as long, and a very short right anterior border which holds the S.m.p. In the S.s.p. there are always some pores close to the external margin.

The S.d.p. is narrow, with a generally convex external margin, a straight internal one with a short anterior segment slanting from the anterior and right part to the leftposterior; in this segment a small pentagonal S.ac.p. plate is placed. The posterior margin of the S.d.p. is always thickened, especially at the internal angle which protrudes behind.

S.s.a. wide, almost as wide as long, with a long straight and reinforced anterior margin, two external borders, the anterior one almost vertical and the posterior moiety, much shorter, slanting to the right. The also thickened internal margin is either convex or divided into two straight unequal segments. Rather numerous pores.

S.d.a. coarse, triangular, about as long as wide. Its slanting anterior-internal margin supports a long S.ac.a. plate. 
The two median plates are well developed and are as shown in the Figures 28-29. The S.m.p. somewhat overlaps the S.ac.p.

All the general plates have a strong, rather dense and irregular porulation extending to the cingulum and to some of the sulcal plates.

Nucleus in the usual form, transversally elongated and curved.

Dimensions: L 37-48.5; A 40-53; Trd. equal to or a little less than $L$. There is a well discernible dorso-ventral compression.

Discussion. Because of the type of $1^{\prime}$, the rather rough aspect, the wide S.s.a. and the long S.p. the most similar species to this new one is $A$. balechii (Steidinger, 1971) Balech, 1985 , which was also found in the same sample. However, it is easily distinguishable by being wider than long, by having a noticeable inclination of the longitudinal axis in lateral view (apparently increased because the epitheca is somewhat more dorsoventrally flattened than the hypotheca) and by the distinctive shapes of all the main sulcal plates. It does not seem necessary to stress the differences from other species because they are too evident.

The epithet is the Latin adjective "foedum", meaning "ugly".

\section{Alexandrium andersoni n.sp.}

Alexandrium andersoni n.sp. (Figs 34-50). Small, broadly oval. Epitheca convex conical, with apex sometimes slightly flattened. Hypotheca hemispherical, usually with an almost imperceptible oblique flattening. Neither sulcal nor cingular lists. Cingulum regularly but not deeply impressed, descending by a little less than one cingular width.

Po oval-triangular; generally with the dorsal margin strongly slanting and almost straight. Foramen slightly marked with a very thin callus.

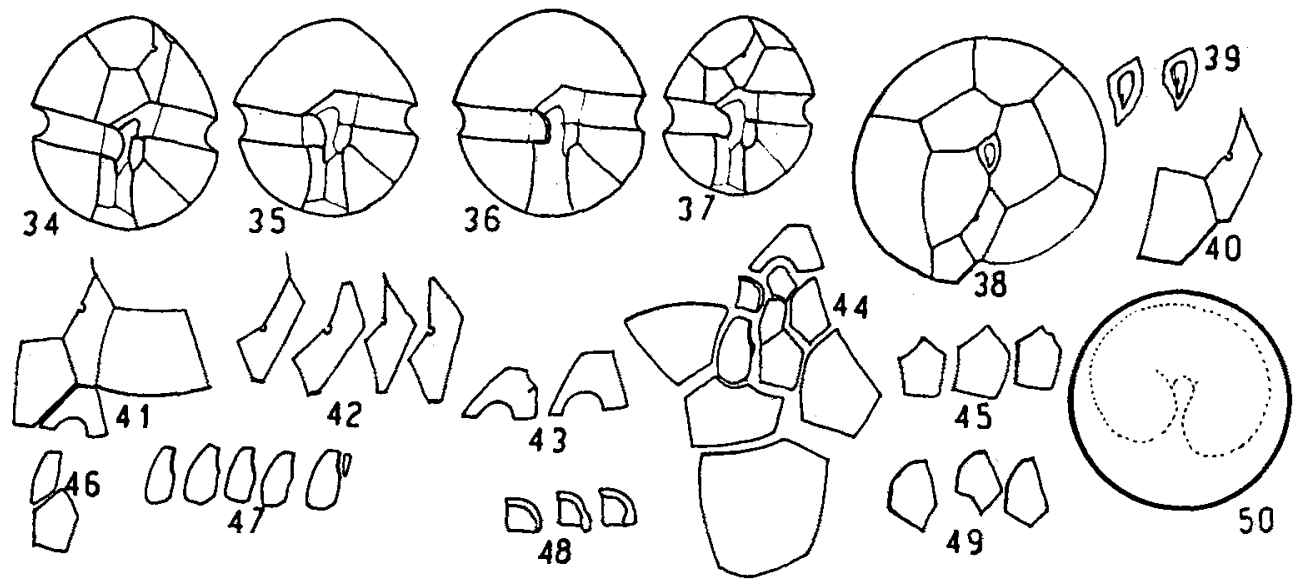

Figs 34-50. Alexandrium andersoni. Figs 34-37: Ventral view; Fig. 38: Epitheca, apical view; Fig. 39: Plate Po; Fig. 40: Plate 6" and 1'; Fig. 41: Plates 6", 1', 1' and sa; Fig. 42: Plate 1' of 4 different specimens; Fig. 43: Sulcal plate sa; Fig. 44: Sulcus with some adjacent plates; Figs 43-49: Sulcal plates; Fig. 45: Plate S.s.p.; Fig. 46: Plates S.m.p. and S.s.p.; Fig. 47: Plate S.d.p. of 5 different specimens, the most right one together with plate S.ac.p.; Fig. 48: Plate S.d.a.; Fig 50: Optical section, showing the very thick and strongly curved nucleus 
Plate 1' narrow, with a small ventral pore; more or less pointed anteriorly and in most of the thecae connected to Po only indirectly by a thread-like formation. Plate $2^{\prime}$ comparatively broad, with a dorsal margin somewhat longer than in most of the species. $3^{\prime}$ hexagonal, rather high and almost symmetrical. In the precingular series, the plate 6 " is very characteristic with two straight and slanting left sides; its cingular border is short, generally equal to or shorter than the anterior one.

In the hypotheca, $1^{\prime \prime \prime}$ is wide; its sulcal margin is but slightly thickened, slightly convex or sinuous and almost vertical for most of its length. The $2^{\prime \prime \prime}$ is longer than wide.

The anterior sulcal plate, S.a., is much wider posteriorly than anteriorly. The anterior border is short and straight to somewhat irregular. The uncinate process is straight and strongly inclined. The posterior notch is wide but not very deep. The left apophysis is rather narrow and also oblique but not as much as the right one.

The S.p. is wider than long. Its main ventral border is divided into two more or less concave moieties which uphold the two posterior lateral plates. Typically, it is slanting posteriorly to the left. To the right there is another ventral border, shorter, straight and slanting in the opposite direction, articulated to the posterior border of 5 "'. The left side of the S.p. is much shorter than the right side.

The S.d.p. is narrow with a short anterior border, the right one being somewhat oblique and a bit convex. The posterior side is in general irregularly convex, sometimes almost straight. The left side is divided into two segments: the anterior one, a bit reinforced, is oblique, and the posterior one, not reinforced, is almost vertical; the oblique or anterior part is almost as long as the posterior one, occasionally longer, and the indentation thus formed is filled with a very tiny and narrow S.ac.p.

The S.d.a. is somewhat variable but in general relatively narrow. The two S.m. plates are well developed. The S.m.p. is characterized by being narrow and longer than in most of the species. The S.ac.a. could not be isolated.

The protoplasm is sparsely pigmented. The cysts, almost of the same shape, are noticeably darker. The nucleus, of the usual C-shape, is very thick and strongly curved.

Dimensions: $\mathrm{L} 21-35$; the majority of the thecae are less than $30 \mu \mathrm{m}$ in length. A 18-33.

Discussion: In spite of the fact that some large specimens (i.e. $>35 \mu \mathrm{m}$ ) are occasionally seen, this species is naturally included in the group of small species, of a rather regular oval shape, longer than wide. It is also allocated to the group of species with $1^{\prime}$ of the normal type, connected to Po, and with a small ventral pore. However, in most of the thecae the anterior end of this plate is pointed and prolonged into a thread connecting it to Po. Because of these characteristics this new taxon seems related to A. minutum Halim. The S.p., wider than long, is a feature shared with $A$. minutum and with the others of the minutum-group. Nonetheless, it differs clearly from them by the shape of all the sulcal plates, especially by the S.a., and by the $6^{\prime \prime}$, both of which are quite characteristic of this new species. In a few other congenerica taxa, like $A$. ostenfeldii, the S.a. has a straight and very slanting right apophysis, but they belong to other groups differing much in size, shape and other details.

It is convenient to stress the quite unusual shape of $6^{\prime \prime}$. This plate, together with the S.a., are features that set $A$. andersoni apart from all other congeneric taxa. The fact that the shape of $6^{\prime \prime}$ is sufficient to identify this new taxon is a lucky circumstance, as thecal analysis is, at least in the material examined, quite difficult due to the tenuousness of the plates. 
The specific name is in honour of Dr. D. M. Anderson, a noted specialist on toxic dinoflagellates, who found and cultures this taxon.

Acknowledgements. It is an agreeable duty to express my thanks to both Dr. Zingone and Dr. Anderson for the samples. I also thank the latter and R. Barbetti for help with the manuscript.

\section{LITERATURE CITED}

Balech, E., 1958. Two new genera of dinoflagellates from California. - Biol. Bull. mar. biol. Lab., Woods Hole 116, 195-203.

Balech, E., 1985. The genus Alexandrium or Gonyaulax of the tamarensis group. In: Toxic dinoflagellates. Ed. by D. M. Anderson, A. W. White \& D. G. Baden. Elsevier, New York, 32-38.

Balech, E., 1988. Una especie nueva del género Fragilidium (Dinoflagellata) de la bahía de Chamela, Jalisco, México. - An. Inst. Biol. Univ. México (Ser. Zool.) 58, 479-486.

Balech, E. \& Oliveira Soares, L., 1966. Dos dinoflagelados de la bahía de Guanabara y proximidades (Brasil). - Neotropica 12 (39), 103-109.

Cox, E. R. \& Arnott, H. J., 1971. The ultrastructure of the theca of the marine dinoflagellate Ensiculifera loeblichii sp. nov. In: Contribution in phycology. Ed. by B. C. Parker \& R. M. Brown. Allen, Lawrence, Kan., 121-136.

Dale, B., 1977. New observations on Peridinium faeroense Paulsen (1905) classification of small Orthoperidinioid dinoflagellates. - Br. phycol. J. 12, 241-253.

Dodge, J. D., 1982. Marine dinoflagellates of the British Isles. Her Majesty's Stationery Office, London, $303 \mathrm{pp}$.

Indelicato, S. R. \& Loeblich, A. R., 1986. A revision of the marine peridinioid genera (Pyrrhophyta) utilizing hypothecal-cingular plates relationships as a taxonomic guideline, - Jap. J. Phycol. 34, 153-162.

Paulsen, O., 1905. On some Peridineae and planktonic diatoms. - Meddr Kommn Havunders. (Ser. Plankton) 1 (3), 1-21.

Steidinger, K. A., 1971. Gonyaulax balechii sp. nov. (Dinophyceae) with a discussion of the genera Gonyaulax and Heteraulacus. - Phycologia 10, 183-187. 